\title{
Linking Foraging Domestic Burglary: An Analysis of Crimes Committed Within Police-Identified Optimal Forager Patches
}

\author{
Eric Halford ${ }^{1}$ (1)
}

Accepted: 6 January 2022 / Published online: 4 February 2022

(c) The Author(s) 2022

\begin{abstract}
Crime linkage is a systematic way of assessing behavioural or physical characteristics of crimes and considering the likelihood they are linked to the same offender. This study builds on research in this area by replicating existing studies with a new type of burglar known as optimal foragers, who are offenders whose target selection is conducted in a similar fashion to foraging animals. Using crimes identified by police analysts as being committed by foragers this study examines their crime scene behaviour to assess the level of predictive accuracy for linking crimes based on their offending characteristics. Results support previous studies on randomly selected burglary offence data by identifying inter-crime distance as the highest linking indicator, followed by target selection, entry behaviour, property stolen and offender crime scene behaviour. Results discuss distinctions between this study and previous research findings, outlining the potential that foraging domestic burglary offenders display distinct behaviours to other forms of offender (random/marauder/commuter).
\end{abstract}

\section{Introduction}

Decision-making by offenders, specifically that which relates to the spatial choice of the offender, is underpinned by several commonly acknowledged key theoretical frameworks including routine activity theory (Cohen and Felson 1979) and crime pattern theory (CPT) (Brantingham and Brantingham 1993). Within a policing context, studies of routine activities and CPT are often applied to direct and control police resources into geographic areas that have suffered high levels of victimisation (Halford 2018). The central concept of such approaches is to maximise the effectiveness of the capable guardianship provided by the increased police presence to prevent and reduce crime in the affected area (Halford 2018). The police commonly use this method to target burglary offenders.

To help develop such patrol plans police commonly use a 3-step process. First, they seek to identify linked crimes committed by the same offender. This is achieved by focusing on crime characteristics to understand which provide the most accurate indicator that two crimes are linked (committed by the same person) or unlinked. This

Eric Halford

ehalford@ra.ac.ae

1 Rabdan Academy, Abu Dhabi, United Arab Emirates area of research is covered in detail later in this section. Second, they look for insights that can help determine the nature of the offending behaviour. Research that has explored the geographical movements of offenders to help define the nature or characteristics of their offending has labelled burglary offenders as 'commuting', those who travel extensively from outside of the attacked area (Canter and Larkin 1993; Rossmo 2000), and 'marauders', who move uncoordinatedly and select targets randomly (Canter 2000; Canter et al. 2000; Rossmo 2000). Finally, they select a theoretical framework on which to base their prediction. There are several theoretical frameworks that the police use to underpin their patrol decision-making which include near-repeat theory that posits that those who live nearest to a recent victim of crime are at the highest risk of becoming a target (Pitcher and Johnson 2011; Ratcliffe and Rengert 2008), and optimal forager theory that indicates they move between patches seeking to maximise the cost-benefit return of offending (Johnson and Bowers 2004a, b), similar to foraging behaviour displayed by animals.

This study adds to the literature in two of the aforementioned areas of research into burglary, namely the area of crime linking and the theoretical framework of optimal foraging theory. The study achieves this by replicating existing studies on crime linking but using the methodologies on a previously unexamined type of burglar, the optimal forager, as to date, this has not been conducted. The purpose 
of doing this is simple. If the police are to use a theoretical framework (optimal forager) on which to base predictions of crime hotspots for patrolling, then it stands to reason that the preliminary crime linkage process should draw upon crime linkage research based on foraging offenders. Doing so will enable the assessment as to whether or not burglars who behave in a foraging manner display distinct characteristics that provide different linkage factors than previous literature that has drawn their data samples from randomly chosen pools of burglary crime data.

To provide a good grounding so that the studies contribution can be appreciated it is necessary to provide an overview of both optimal forager theory and crime linking literature. Optimal forager theory argues that offenders will act much the same way as a predator (Addis 2012; Fielding and Jones 2012; Johnson and Bowers 2004a, b). The optimal forager theories roots lie within ecology where it is found that foraging behaviour is driven by a need to find resources but is weighted against the risk of mortality (Pyke et al. 1977; Pyke 2019 and Rodriguez et al. 2019). In an effort to reduce the risk, foraging animals return to the same known areas but switch between patches based upon complex factors such as abundance of prey, level of predation risk and energy expenditure (Charnov 1976). A criminal will consider the same issues when searching for a victim by calculating the travel time, hour of day or night, risk of detection or apprehension vs. the potential for criminal reward and the level of effort required to achieve it (Johnson 2014). When making these calculations Johnson et al. (2008) theorised that both the animal and criminal will display similar foraging behaviour as they search for their prey or victim. It is suggested that the two foraging principles that they will adopt are the central place foraging approach (Johnson 2014) where the offender will conduct their searching based around a specific base or home and as such their prey will fall within their routine activity node (Orians and Pearson 1979), or the optimal patch where the offenders behaviour will be dictated by the amount of time available to forage combined with their knowledge and previous success in a certain area (Pyke 1977, 2019). The theory of bounded rationality suggests such complex forms of decision-making within criminal offenders are unlikely (Johnson and Payne 1986 and Opp 1997), suggesting instead that simple heuristics are at play. Studies of burglars have, however, argued that experienced offenders do make complex decisions regarding offending behaviour (Nee and Meenaghan 2006 and Taylor 2014), even if it is conducted heuristically. Accepting this theoretical argument it is worth noting that the criminogenic application of optimal forager theory does not seek to dissect the complexity, or otherwise, of the decision-making process, and only to predict the final outcome, namely the offending patch.

When considering the foraging patch it is suggested that areas that are closer together are more likely to be similar in their abundance of prey or victims and as such a clustering effect emerges similar to the underpinning theory to the near-repeat approach and what provides the potential to predict future victims (Fortin and Dale 2005) but with a subtle distinction. Figure 1 shows a theoretical scenario of how a forager moves between areas which are defined as 'patches' (Charnov 1976). It can be seen in Fig. 1 that foraging patches rarely overlap and in fact are often distinct microgeographical areas. Identification of similar behaviour in the spatial distribution of domestic burglary crimes is indicative that the offender is behaving in a foraging manner, as opposed to simply targeting nearby victims. This is a subtle but important difference to near-repeat theory which includes significant overlapping of targeted victim locations.

Since its emergence the optimal foraging theory has achieved momentum within policing and is now one of the most commonly used predictive policing approaches within the UK, used by as many as 9 police services (Halford 2018). As we have outlined, in the UK the optimal forager patch prediction is the final step, in a 3-step process used to direct police resources into areas predicted as high risk for future domestic burglary, which is used as a crime reduction and prevention tactic. Police analysts presently identify the presence of a foraging burglary offender through the identification of previously committed, linked, serial offences that occur in clusters within non-overlapping geographic patches (Halford 2018). Using the aforementioned criteria, the prediction of the future foraging patch is then based upon the professional judgement of the police analyst (Halford 2018). However, before this stage can be reached, step 1 must be conducted and all burglary crimes within the localised area must be examined to identify those which are linked to a prospective forager. Similar to other forms of crime linkage, the linking of crimes which are attributed to a foraging offender is presently based upon professional judgement

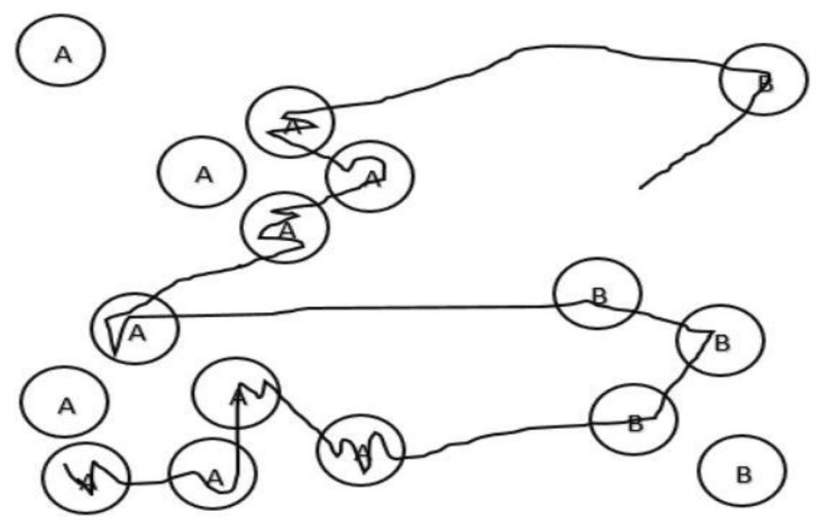

Fig. 1 Optimal foraging patch selection ( adapted from Charnov 1976). The offender spends time in a variety of patches, committing crime in those deemed suitable (A) and travelling through those deemed unsuitable $(\mathbf{B})$ 
of a police analyst (Burrell and Bull 2011; Mugford and Martineau 2014 and Pakkanen et al. 2012) which can be open to influence from bias, misinformation and inaccuracy (Woodhams and Davies 2019).

Once analysed, linked and predicted, police analysts produce an 'optimal forager' briefing product which contains maps of areas predicted as being at heightened risk of burglary. These are then used to co-ordinate the deployment of police resources. This could be argued to be an overly simplistic and unscientific approach, and it stands to reason that the accuracy of such predictions is likely to increase if the accuracy of the crime linking step is improved. This is why this study seeks to examine the police predicted forager crimes for potentially unique behavioural and physical characteristics to improve the process of linking used to underpin the police optimal forager analysis. If foraging offending can be confirmed with greater accuracy through improved crime linking, it will then be possible to more accurately predict their future foraging patch, theoretically enabling the police to more effectively target their predictive responses. To further the knowledge in this area this study replicates previous similar research completed on serial burglary offenders (Markson et al. 2010) which examined modus operandi, temporal and spatial factors. This studies novel contribution is that it goes further than the previous study outlined and examines a wider range of offending behavioural and physical characteristics displayed by burglary offenders, and is focused on those specifically identified by the police as foraging burglars, to identify which provide the greatest accuracy in terms of crime linking.

Traditionally the most beneficial method for linking crimes prior to conviction is through forensic evidence such as DNA, fingerprints or footwear impressions, and when available, CCTV evidence (Rossmo 2000). However, the fact that as little as $5.2 \%$ of all theft-related offences (including burglary offences) were detected by police services in the UK in the year ending September 2020 (ONS 2021) indicates that the presence of such evidence is unfortunately rarer than one may think. As Bennell and Jones astutely outline:

"Without such physical evidence, linking crime scenes may hinge solely upon behavioural information revealed through examination of crime scene characteristics and offence locations" (Bennell and Jones 2005: 23)

In practical application, crime linkage utilises the theoretical principle that when an offender commits a crime they repeat certain behaviours or target victims based on previously successful crimes. To link two crimes or identify a crime series an individual must examine them in detail and identify factors which contribute to the conclusion that they are linked. This is fraught with danger if it is done without the backing of any empirical analysis as it could lead to both false positives and missed opportunities (Tonkin 2012). If this occurred in an operational environment the subsequent forager prediction produced and the direction of police resources from that information is less likely to be effective.

Despite its importance, until recently only limited academic research had been conducted that examined the effectiveness of crime linkage through non-tangible information such as behavioural characteristics, target selection and offence location (Bennell and Jones 2005; Bennell and Canter 2002; Santtilla and Korpela et al. 2004 and Tonkin et al. 2008). It is only within the last decade that the field of crime linkage has begun to forge its own corner within criminological study and this has been enabled and supported by extensive further research (Albertetti et al. 2013; Bennell et al 2010a, b; Borg et al. 2014; Bouhana et al. 2016; Fox and Farrington 2014; Woodhams et al. 2019; Reich and Porter 2015; Salo et al. 2013; Tonkin 2012; Tonkin and Woodhams 2017; Turvey and Freeman 2016; Wang et al 2015 and Zoete et al. 2015) and creation of a dedicated crime linkage international network (C-LINK, 2021). What a number of these previous studies have suggested is that contrary to what one might expect it is actually inter-crime distance, as opposed to the modus operandi of an offender (Bennell and Jones 2005: 23) which is the most accurate linkage feature, particularly when researching serious acquisitive crime such as burglaries and stealing from motor vehicles (Bennell and Jones 2005; Bennell and Canter 2002; Davies et al. 2012; Santtilla and Korpela et al. 2004; Tonkin et al 2008; Tonkin et al. 2008; and Tonkin 2012).

\section{Research Aim and Hypothesis}

This study continues the previous works and hypothesises that serial foraging criminals display distinct behavioural and/or physical characteristics within their offending. Its primary aim is to examine the offending behavioural and physical characteristics displayed by offenders identified by the police analyst as foraging burglars to identify which provide the greatest accuracy in terms of crime linking. Doing so provides three outcomes (1) a methodology for police analysts to utilise to more accurately link offences committed by foraging offenders and other forms of burglary offender, (2) post-analysis, the results could provide decision-making thresholds to underpin the professional judgement-based linkage analysis that underpins the forager predictions, (3) 
finally, it continues to add to the knowledge base within crime linkage by providing an analysis of linked offences committed by suspected foraging burglary offenders to compliment other existing studies.

\section{Data and Methods}

The data used in this study come from a total of 2916 recorded crime records. These crimes were extracted from 50 optimal forager briefing products. A briefing product is a document used by analysts that contains maps of 'forager patch' locations predicted as being at risk of victimisation and include additional information that describes the linkage rationale and key offence behaviour's or characteristics. The briefing documents used were operational products that were all created by analysts within Lancashire constabulary and were used to direct 'real-world' police patrols. The methodology used by the analysts for identifying the optimal forager patches is achieved through the identification of previously committed, linked, serial offences that occur in clusters within non-overlapping geographic patches (Halford 2018), which then informs the analysts prediction of a future patch. All of the high-risk areas highlighted within the products had been specifically identified by the analyst as optimal forager burglary patches. From within the briefing products 2916 domestic burglary crimes were identified that were specifically committed inside the foraging patch area identified by the police analyst. From those crimes, only 874 had an offender identified. For a pair to be defined as linked the offender must have been convicted. By adopting this strict criterion this study was able to make conclusions on data that has already surpassed a high burden of proof. Of those crimes 152 different offenders were identified. A subcategory of only 53 offenders committed 8 or more offences and these made a natural sample group. As such, 3 offenders were weeded at random leaving 50 offenders who each accounted for 4 pairs, from different patches (a total of 8 crimes). This created a total of 200 linked pairs (400 crimes) of domestic burglary offences. The 400 crimes were then subjected to logistic regression and receiver operator characteristics analysis.

To enable the analysis process each set of linked crimes were coded using a binary format where 1-1 refers to the first crime committed by offender 1 and $1-2$ refers to the second, for example; $1-1,1-2,2-1,2-2,3-1,3-2,4-1$, 4-2 and so on for each of the identified crime pairs. Each pair of linked crimes then had the behavioural and physical characteristics present recorded against them as $0 \mathrm{~s}$ and $1 \mathrm{~s}$, with 0 indicating absent and 1 indicating presence. This data were then analysed using a bespoke crime linkage software programme called B-Link which has been used to conduct such crime linkage in other published studies (Bennell and Jones 2005; Bennell and Canter 2002; Markson et al. 2010 and Tonkin 2012). The B-Link system calculated the coefficients used in this study by completing the following functions; (a) it creates all possible crime pairs, (b) it indicates whether the pairs that are constructed are linked (1) or not (0), and (c) and then calculates a variety of different crime similarity scores for each crime pair based on the data that were coded, for example; property stolen, in the input file. In total 79,800 possible permutations were analysed. On completion, the B-Link system then provides data based on a variety of statistical analysis including simple matching, Jaccard's coefficient, Yule's Q, Pearson's phi and Sorensen-dice. For the purpose of this study, Jaccard's coefficient was selected for reporting results as this has been utilised in studies the analysis replicates (e.g. Bennell et al. 2010a, b and Ellingwood et al. 2013). It has been suggested this is used due to the fact that it is simple and efficient (Melnyk et al. 2011). For example, Ellingwood et al. (p2, 2013) outline that "for a pair of crimes ( $A$ and $B$ ), $J$ is where a equals the number of behaviours common to both crimes, and $\boldsymbol{b}$ and $c$ equal the number of behaviours unique to crimes $A$ and $B$, respectively". This captured in the formula below;

$$
J=\frac{a}{a+b+b}
$$

\section{Logistic Regression Analysis}

Because of the simplicity of the main question being asked in this study 'are two crimes linked or not?' and the potential multiple outcomes, crime linkage lends itself well to forms of analysis that can analyse several variables. Regression analysis has shown itself to be a valuable tool in analysing variable data (Chatterjee and Price 1991:1 and Peng et al. 2002). This is because it offers an easy and simple method for analysing the relationships between variables (Peng et al. 2002). As such, this method was used to assist in the identification of the probability of an outcome between several variable factors. The prediction of the final dichotomous outcome being sought, i.e. are these two crimes linked, is largely reliant on variables which can change dependent on the scenario (Chatterjee and Price 1991:1, Peng et al. 2002). Scenarios where the relationship between the dependent variable and a number of independent variables is examined are referred to as multiple regression analysis (Chatterjee and Price 1991), and this is the depth of regression analysis that this study used. As it pertains to this research the dependent variable or dichotomous outcome that is to be identified is simply whether or not two crimes are linked. The independent variables that will be utilised to assist in identifying the positive likelihood of this factor will be the characteristics of the crime scenes. These characteristics will be both behavioural and physical and are outlined in detail in Table 1 . 
Logistic regression analysis centres around the concept of the logit which is an odds ratio which in its most basic form is derived from a $2 \times 2$ contingency table which would pit predicted outcomes versus actual outcomes (Peng et al. 2002:3). In the scenario of linking two crimes together this would be (the prediction that the crime is linked or unlinked) ( $\mathrm{x}$ ) (the reality that it is linked or unlinked). Combining these two statements, as outlined by Bennell and Canter, provides four possible options with two being positive and two being negative (2002). Bennell and Canter outline that these positive and negative results are referred to as hits, correct rejections, false alarms and misses (2002) and are shown in Fig. 2. Firstly, the hit would indicate that two crimes have successfully been identified as being linked. The false alarm indicates that a hit has occurred when in fact it has not. A correct rejection simply means that the crimes being examined have been identified as being unlinked and finally the miss means that two crimes have incorrectly been identified as being unlinked when in fact they are. By studying both the behavioural and physical characteristics of a crime as previously outlined the study will seek to identify what is statistically the most likely conclusion, i.e. a hit and a correct rejection. Logistic regression analysis is well suited for this task as it will provide an odds ratio that the user will be able to base their decision-making upon.

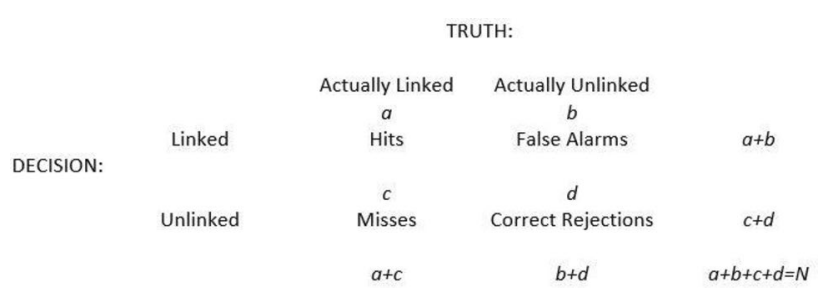

Fig. 2 Example decision outcomes ( adapted from Bennell and Canter 2002)

\section{Receiver Operator Characteristics (ROC) Analysis}

Receiver operator characteristics analysis is used to identify information thresholds that can aid in diagnostic decisionmaking (Swets et al. 2000). It is in this context that the technique is used within this study. Several studies have been done to date using this technique to compliment the regression analysis used to predict crime linkage and calibrate the validity of crime linking features. Combining these enables the production of decision-making thresholds (Bennell and Canter 2002 and Bennell and Jones 2005). Bennell and
Table 1 Physical and Behavioural Linkage Indicators

\begin{tabular}{ll}
\hline Variable Examined & Criteria of the Variable \\
\hline Entry Behaviour & Entered via the Front, Side or Rear, entered via the \\
& Entered via Insecure Window, Patio Doors, Door \\
& Forced Entry via Window, Door \\
& Entered by climbing \\
& Smashed a Window, Door \\
& Used Tools, Lock snapping \\
& Distraction \\
& Entered via Garage, Entered via Attic, \\
& Removed Beading or Window Entered via a cat flap \\
& Conduct a Tidy Search \\
& Conduct an Untidy Search \\
& Committed Criminal Damage \\
& Used a Motor Vehicle \\
& Wore Gloves, Used Violence or Weapons \\
Oultiple Offenders & Cash, Jewellery, Precious Metals, Electronics, Motor Vehicles or \\
Keys, Identification and Copper \\
Onter-crime distance & Occupied Caravans \\
Pungalow, Apartment or Flat \\
End Terrace, Mid Terrace \\
Semi-Detached, Detached \\
Rural, Suburban \\
Overlooked, Secluded \\
Old (Pre-1940) \\
New Build (Less Than 10 Years) Contemporary (1940-2006) \\
Monday - Sunday \\
24 HRS (4 h Intervals) \\
Up to 6KMs (highest range in the sample between linked crimes) \\
\\
\end{tabular}


Canter (2002) outlined that a decision-making threshold is important in the absence of any categorical linking criteria such as forensic evidence. This is because it provides a 'cutoff point' whereby a layman can deduce that any reading above that figure can imply a positive decision, which in this study would mean that two crimes are linked (Swets 1992). The threshold analysis is also important because although regression analysis may be able to provide us with some surety regarding the linkage likelihood of two crimes, what it cannot do is put this result into context. ROC analysis can provide this context by offering an easy to understand result that measures between 0 and 1 . The key statistic in ROC analysis is the area under the curve (AUC). This represents the predictive accuracy of the data that give rise to the ROC curve; in this case, the criminal behaviours and characteristics used to deduce if crimes are linked (committed by the same person). For instance, an AUC of 0.0 indicates certainty the behaviours and characteristics are not suitable as indicators that crimes are linked. An AUC of 0.5 indicates that the data do not perform any better than chance, whereas an AUC of 1.0 indicates perfect prediction that presence of these factors indicates the crimes are linked and provides $100 \%$ certainty they are committed by the same offender. In reality, only forensic evidence could achieve this high bar. However, lesser results, such as 0.7 out of 1 for example, are far above chance and would allow the decision maker to make a judgement (Bennell and Jones 2005). Based on this methodology, the desired outcome is a high AUC. The $\mathrm{p}$ value indicates whether the AUC result is statistically significant.

\section{Analysis}

Once compiled, the linked and unlinked crimes were then examined and key behavioural and physical characteristics extracted to be analysed using the B-Link and SPSS statistics programs. Prior to analysing the crimes, it was necessary to identify the categories of behaviours and physical characteristics within them. Previous studies have broadly defined and grouped these together as entry behaviour, property stolen and target selection, and included time of the offence and inter-crime distance (Bennell and Jones 2005; Bennell and Canter 2002 and Tonkin 2008) with the latter two being the most accurate. As these areas have been previously identified through a tested pool of studies these headings were again used to collate the behavioural and physical characteristics of the offences. In addition to these categories a further category of 'offender behaviour' was created to further knowledge in this area. Although this broad category heading (offender behaviour) has been studied before, the novel contribution of this study is that it contains certain behaviours such as the use of gloves, a vehicle or violence (as outlined in Table 1) in the commission of the offence that have never previously been examined in this context. The individual behavioural and physical characteristics are outlined in Table 1. These particular behaviours and characteristics were grouped under these headings because this is how they are captured on the crime input computer system during the recording process. As such there was no requirement for further coding to identify which required grouping under which heading as this was dictated by the recording process itself. There was additional information provided by the officers in a free text area, but this was not analysed within this study.

To then assess how accurately you can discriminate between the linked and unlinked crime pairs provided in the B-Link output file the data are analysed further using the regression analysis function within the software SPSS. This analysis shows how good each behavioural and physical characteristic is at distinguishing between linked and unlinked crime pairs. To complete this process, the Jaccard's coefficient was selected as it was identified as the most useful tool for statistically assessing the similarity between binary attributes, in this case physical and behavioural characteristic of linked dwelling burglary offences committed by serial foraging offenders. A separate Jaccard's coefficient was calculated for entry behaviour, offender behaviour, property selection and target selection, and these were entered alongside inter-crime distance as variables in the logistic regression. SPSS subsequently provided an output of this analysis informing how useful each indicator is as a linking variable. To conclude the analysis, the logistic regression data were then re-analysed again using SPSS to conduct the receiver operator characteristic analysis resulting in production of charts displaying the area under the curve (AUC) and accompanying confidence data for each behavioural and physical category.

\section{Results}

In relation to the logistic regression analysis Table 2 shows that all of the examined behavioural and physical characteristics examined were found to have a high degree of predictive accuracy (as measured by Wald's statistic) and a satisfactory fit with the data. However, it was a combined model that included both target selection and inter-crime distance that produced the highest logit and predictive accuracy, closely followed by that of the individual models for target selection and inter-crime distance, which was the reason these two models were combined in an effort to produce an optimal model.

Results from the ROC curve analysis are outlined in Table 3. The graphs relating to these findings can be seen in full in Appendix 1. The ROC curve charts that illustrate 
Table 2 Behavioural and Physical Characteristics Logistic Regression Analysis Comparison

\begin{tabular}{|c|c|c|c|c|c|c|}
\hline Linkage Predictor & Constant $X(S E)$ & & Logit $\beta$ (SE) & Wald's (df) & Nagelkerke $\mathbf{R}^{2}$ & Model $\chi 2$ \\
\hline $\begin{array}{l}\text { Combined (Target Selection/ } \\
\text { Inter-Crime Distance) }\end{array}$ & $-7.817(0.138)$ & $5.819(0.247)$ & & $557.02(1)^{* * *}$ & 0.145 & 18.132 \\
\hline Target Selection & $-7.381(0.137)$ & $4.361(0.268)$ & & $265.4(1)^{* * *}$ & 0.07 & $19.185^{*}$ \\
\hline Inter-Crime Distance & $-8.310(0.244)$ & $4.157(0.255)$ & & $265.18(1)^{* * *}$ & 0.214 & $8.267 *$ \\
\hline Entry Behaviours & $-6.660(0.109)$ & $2.305(0.205)$ & & $126.01(1)^{* * *}$ & 0.03 & 5.206 \\
\hline Property Selection & $-6.225(0.093)$ & $0.868(0.176)$ & & $24.282(1)^{* * *}$ & 0.08 & 1.287 \\
\hline Offender Behaviour & $-6.272(0.099)$ & $0.734(0.144)$ & & $26.146(1)^{* * *}$ & 0.019 & $6.351 * *$ \\
\hline
\end{tabular}

$S E$ Standard Error, $d f$ Degrees of Freedom, $* p<0.05$, ** $p<0.01, * * * p<0.001$

the area under the curve can be seen in Figs. 2, 3, 4, 5, 6, 7 and 8. An AUC of 0.5 indicates that the result is approximately the same as chance alone. An AUC of 1.0 indicates perfect discrimination and means that the larger the AUC, the higher the predictive accuracy (Woodhams et al. 2019). AUCs of between 0.5 and 0.7 are indicative of low levels of accuracy, 0.7 to 0.9 indicate moderate levels of accuracy and 0.9 to 1.0 high levels (Bennell and Jones 2005; Swets 1992).

Inter-crime distance was shown to be the most effective predictor of crime linkage of foraging dwelling burglary offenders and provided the greatest AUC. This was in line with previous studies conducted in respect of randomly selected linked burglaries (Bennell and Canter 2002 and Bennell and Jones 2005). However, the link in respect of predicted foraging offenders was slightly less $(\mathrm{AUC}=0.89)$ than that that identified in previous studies (Bennell and Jones 2005) of linked dwelling burglaries (AUC $=0.90$ ). In respect of target selection, previous studies (Bennell and Jones 2005; and Tonkin et al. 2011) examining randomly selected linked burglary dwellings have identified wide varying degrees of prediction accuracy in respect of target selection, with AUCs of 0.58 and 0.73 , respectively; however, both were below the results identified within this study (AUC $=0.76$ ). In an effort to optimise the predictive accuracy the two optimal characteristics of target selection and inter-crime distance were combined. The combined characteristics produced a strong logit result indicating increased predictive accuracy and suggesting that crimes committed can be more accurately predicted as linked when the inter-crime distance and target selection characteristics are considered together. When ROC analysis was also conducted a reduced standard of error was also achieved than that of target selection alone, and the confidence interval ranges also improved but was still below that of inter-crime distance, as was the strength of the AUC. This was an unexpected result but one that has likely occurred due to the goodness of fit of the data which was non-significant.

The remaining models of entry behaviour, property selection and offender behaviour produced low levels of predictive accuracy. As has been outlined earlier in this section other studies (Bennell and Jones 2005) have suggested that traditional entry behaviour characteristics are one of the lowest $(\mathrm{AUC}=0.59)$ in terms of predicting linkage of dwelling burglaries. However, this study places it above property selection $(\mathrm{AUC}=0.59)$ and offender behaviour (AUC $=0.58$ ) with an AUC of 0.66, this is 0.07-0.08 above these indicators, respectively, and greater than other similar studies on randomly selected linked dwelling burglaries, but still remains a low level of predictive accuracy. In respect of property selection, the type of stolen property that a foraging burglar aims for provided a very low level of predictive accuracy (AUC $=0.59$ ). This is not a surprising result and is in line with other studies into randomly selected linked
Table 3 Behavioural and Physical Characteristics Area Under the Curve Comparison. Graphs can be located in Appendix 1

\begin{tabular}{|c|c|c|c|c|}
\hline \multirow[t]{2}{*}{ Linkage Predictor } & \multirow[t]{2}{*}{ AUCa } & \multirow[t]{2}{*}{ SEb } & \multicolumn{2}{|c|}{ 95\% Confidence Interval } \\
\hline & & & Lower Bound & Upper Bound \\
\hline Inter-Crime Distance Overall & $0.89 * * *$ & 0.01 & 0.87 & 0.91 \\
\hline $\begin{array}{l}\text { Combined (Target Selection/Inter- } \\
\text { Crime Distance) }\end{array}$ & $0.84 * * *$ & 0.01 & 0.81 & 0.87 \\
\hline Target Selection & $0.76 * * *$ & 0.02 & 0.72 & 0.79 \\
\hline Entry Behaviour & $0.66 * * *$ & 0.02 & 0.61 & 0.70 \\
\hline Property Selection & $0.59 * * *$ & 0.02 & 0.54 & 0.63 \\
\hline Offender Behaviour & $0.58 * * *$ & 0.02 & 0.54 & 0.62 \\
\hline
\end{tabular}

$A U C$ Area under the curve, SE Standard Error, ${ }^{*} p<0.05, * * p<0.01, * * * p<0.001$ 
dwelling burglaries and commercial burglaries (Bennell and Jones 2005) who predicted AUCs of 0.59 and 0.58, respectively. The results from this study suggest that out of all potential behavioural and physical characteristics researched that offender behaviour provides the lowest level of discriminatory predication ( $\mathrm{AUC}=0.58$ ). This is a level that is barely above that predicted by chance.

\section{Discussion}

This study has filled a small gap that existed within the literature, admittedly related to a niche area of criminology, but one that is presently widely used by police services in the UK to underpin their patrol decision-making. In doing so it has raised some interesting discussion points. The findings may prove useful for future research and operational use alike. Unsurprisingly, the study identified that inter-crime distance remains the most accurate indicator that crimes are linked, even for foraging offenders. This is in line with multiple previous studies (Bennell and Canter 2002 and Bennell and Jones 2005) not focused on foraging offenders but provides a strong indicator that this form of dwelling burglary offender does not commit their burglary offences in geographical areas that overlay one-another. If they did, then much lower scores of predictive accuracies would have been seen, but this was not the case. This suggests that foraging behaviour is occurring and is operating in a patch selection manner as described by Charnov (1976) and outlined in Fig. 1. It also indicates that increased capable guardianship in the form of police patrols in predicted forager areas is likely to be an effective response that could reduce or prevent crimes committed by foraging offenders.

Although the personal behaviour of foraging burglary offenders has previously been researched in isolation in respect of its ability to predict linkage between offences, previous studies have categorised these personal behaviours as 'entry behaviour' or 'target selection behaviour' to define what is commonly referred to as a modus operandi or MO (Bennell and Canter 2002; Davies and Tonkin et al. 2012 and Tonkin and Grant et al. 2008). This study disconnects the physical entry characteristics from other behaviours displayed by the offenders while committing the crime and as such provides new insights on behaviour committed by burglars during the offence. Only one other study has attempted to do this by examining the internal search behaviour of offenders (Tonkin et al. 2011) in which a strong discriminatory prediction accuracy was identified (AUC $=0.66$ ). This study however identified a very low predictive accuracy from analysing the personal behaviour of the foraging offenders. As a result, this suggests that as a decision-making threshold for practitioners conducting the linking process, the MO may not be as robust a linkage indicator as previously believed.
That said, one possible explanation for this result is that all but one of the offender behaviours in this study are reliant on being identified by either eye witness evidence, i.e. multiple offenders and use of a motor vehicle, or being identified thorough forensic examination of the scene, i.e. the wearing of gloves to mask the presence of finger prints. As such it is not possible to generalise as to whether these characteristics are unreliable linkage factors in respect of foraging burglary offenders, all burglary offenders alike, or is purely down to their absence due to a lack of witnesses or positive forensic results. This study also identified that entry behaviour was far more accurate in identifying linked cases than has previously been seen and in this study, higher than both offender behaviour and property selection. This is a potential important finding as it suggests that the type of burglary offending (in this study it is foraging) may have an impact on the linkage accuracy of behavioural and physical characteristics. In an operational context this means that if analysts spend greater time applying scrutiny to identifying the form of offending, i.e. foraging, commuting, random or organised burglary offending, it will better inform the linking process by providing them a more evidence-based decision-making threshold, potentially increasing the accuracy of their linkage predictions.

In respect of property selection, this study was firmly in line with previous findings and indicates that foraging burglary offenders do not display increased preference of property selection than any other form of offender. It is highly likely that as Bennell and Canter have previously argued (2002) that indicators that offenders have least control over provide the lowest accuracy in terms of linkage prediction. Property stolen is one of these indicators as ultimately what is stolen is controlled by the property available, which is highly likely to be incredibly similar between homes. Furthermore, they are often intrinsically linked together. For instance, cash, vehicle keys and identification are all property items that are frequently located together within a handbag, purse or wallet and as such, difficult to distinguish as a behavioural characteristic meaning its use as a decisionmaking threshold for linkage prediction may be limited.

As alluded to above, this section suggests the potential that the form of burglary offender can be identified from their behaviours and subsequently used to inform linkage models and spatial offending predictions made. This approach could possibly be used to identify an offender as a forager, who moves between patches seeking to maximise the cost-benefit return of offences as outlined by Johnson and Bowers (2004a, b), or the commuter, who travels extensively from outside of the attacked area, as identified by Rossmo (2000), the marauder, who moves uncoordinatedly and selects targets randomly, also identified by Rossmo (2000) and the organised burglary criminal. It may of course be possible for an offender to possess 
characteristics of more than one type of offender, and as such this study suggests that further research is required to assess whether this argument holds true. It could be argued that in reality, this is hard to conduct without first knowing where the offender lives. However, experience indicates that there are often elements of investigations that can enable distinction without successfully identifying the home of the offender, for example, if a vehicle is involved in the offences tactics such as automated number plate reading could identify the suspects have travelled an extensive distance and as such, could be considered a commuting offender. Similarly, this concept could be tested retrospectively by examining detected crimes committed by commuting offenders if a defined parameter could be set, i.e. offenders who travel more than 10 miles could be classified as a commuter for the purpose of exploring this avenue further. The value in this further research is that if it does hold true, it can then enable researchers and practitioners alike to potentially distinguish between types of burglary offenders, and as a result, apply bespoke models of prediction and improve linkage decision-making. For example, boost near-repeat theory may be more appropriate as a predictive methodology for random-marauding offenders, and the optimal forager method may be more suitable for foraging burglars, the offender type being distinguished by low or high levels of linkage accuracy in respect of entry and target behaviour (boost near-repeat offenders displaying lower linkage accuracy in both for example). The suggestion that different types of burglars display different behaviours when committing and selecting their crimes has been studied. Fox and Farrington (2012) examined burglary offenders in the context of behaviours that were organised, methodical, disorganised, chaotic, and opportunistic and found there to be distinct evidence supporting the position that not all burglars were created equally. What this study did not do is attempt to classify these within known methodologies for predicting burglary locations or in the context of spatial decision-making, as this study now proposes.

To conclude, this study does possess several key limitations which must be taken into account when considering the findings. Firstly, the data within this study were only obtained from within one police force that utilises the optimal forager predictive policing methodology when there are believed to be as many as nine actively using the method (Halford 2018). Furthermore, free text data from within the recorded crimes analysed were not examined which may have provided greater insight. More detailed analysis coding the criteria within each individual characteristic and behaviour could provide further insight than this study has achieved as it only compared them as clustered groups. Significantly, the study was also heavily reliant on the work conducted beforehand by police analysts who had complete autonomy to identify offences as being conducted by a foraging burglar and the prediction of the hotspot patches they predicted, which all of the analysed crimes were taken from. As this was done using professional judgement the data may have included false positives and omitted others as a result of a false-negative decision. Future research that encompasses data from more police forces, widens its collection to include free text data and/or, enhanced coding of each specific characteristic would help confirm or refute findings within this study. Furthermore, further research on examining definable profiles of burglary offenders and their crime linkage characteristics would advance the suggestion that they display distinct characteristics that can be aligned to alternate predictive methodology and continue to add to the body of knowledge in respect of foraging offenders.

Funding I can confirm that no funding or grants have been received to support this study.

\section{Declarations}

Ethical Procedure The research meets all applicable standards with regard to the ethics of experimentation and research integrity, and the paper has been submitted following due ethical procedure, and there is no duplicate publication, fraud, plagiarism, or concerns about any of the included forms of experimentation.

Informed Consent During the conduct of this study no identifiable personal data has been. As such, no identifying details (names, dates of birth, identity numbers, biometrical characteristics (such as facial features, fingerprint, writing style, voice pattern, DNA, or other distinguishing characteristic), and other information) have been examined or utilised and are not contained within the study. As such, under these conditions consent was not required consent as the submission does not include any identifiable data and/or images that may identify any person. In addition, to affirm this ethical conduct of the study was assessed and confirmed prior to conduct and consent to publish has been agreed by the data provider.

Conflicts of Interest As the author of this paper I can confirm I have no financial or personal relationship with other people or organizations that could inappropriately influence or bias the content of the paper. In respect of professional conflicts, the only potential points of interest here are (1) That Dr Craig Bennell supplied me the computer software B-link to assist with this study as part of my Ph.D and (2) Dr Ray Bull has previously seen a preliminary proposal presentation on elements of my study in the UK as part of a seminar he attended in approximately 2016 at Birmingham University.

Research Involving Human and Animal Participants This article does not contain any studies with human participants or animals performed by any of the authors.

Open Access This article is licensed under a Creative Commons Attribution 4.0 International License, which permits use, sharing, adaptation, distribution and reproduction in any medium or format, as long as you give appropriate credit to the original author(s) and the source, provide a link to the Creative Commons licence, and indicate if changes were made. The images or other third party material in this article are included in the article's Creative Commons licence, unless indicated 
otherwise in a credit line to the material. If material is not included in the article's Creative Commons licence and your intended use is not permitted by statutory regulation or exceeds the permitted use, you will need to obtain permission directly from the copyright holder. To view a copy of this licence, visit http://creativecommons.org/licenses/by/4.0/.

\section{Appendix 1}

\section{Receiver Operating Characteristics}

Fig. 3 Entry Behaviour ROC Curve

Fig. 4 Inter-Crime Distance ROC Curve
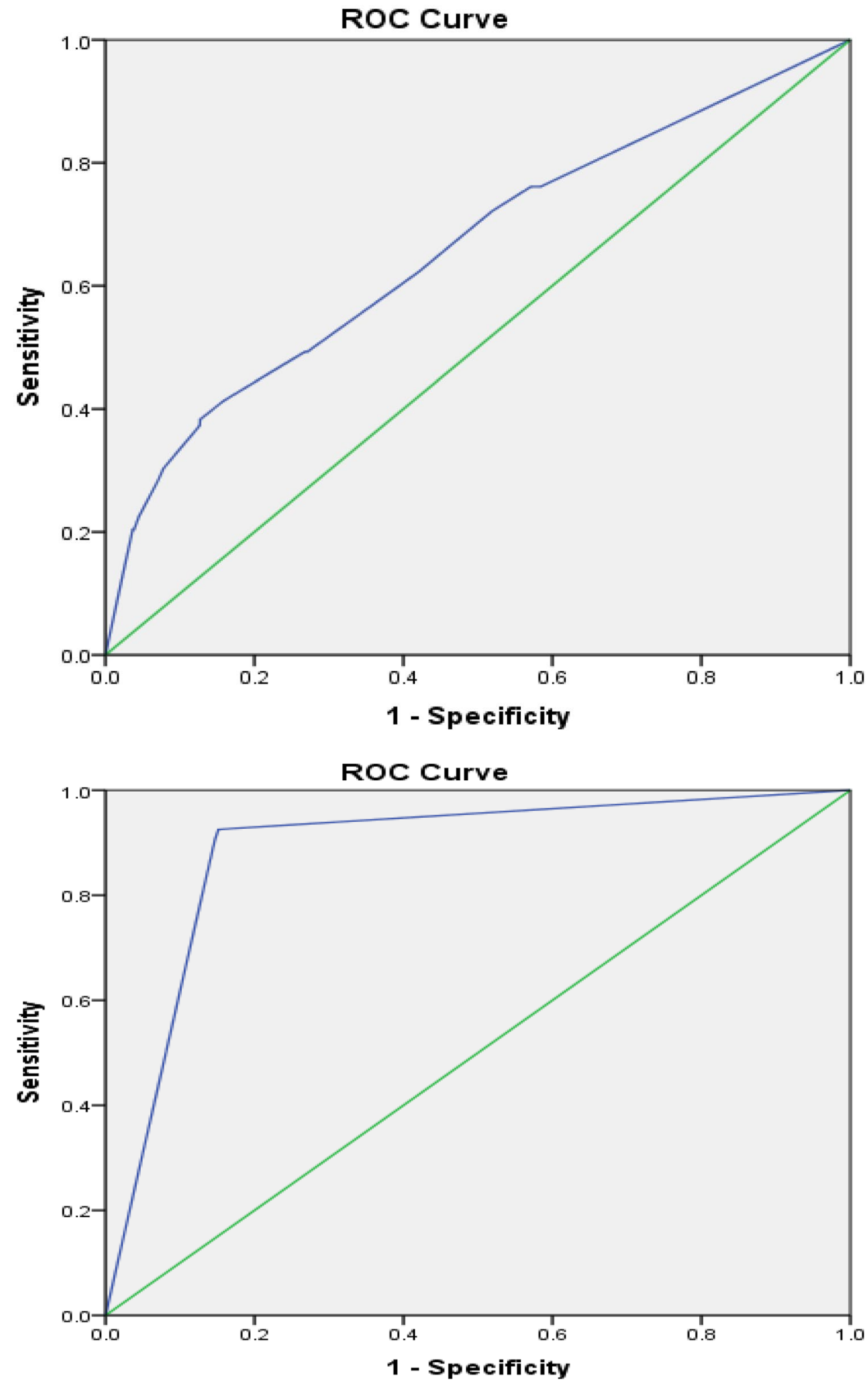
Fig. 5 Offender Behaviour ROC Curve

Fig. 6 Property Selection ROC Curve
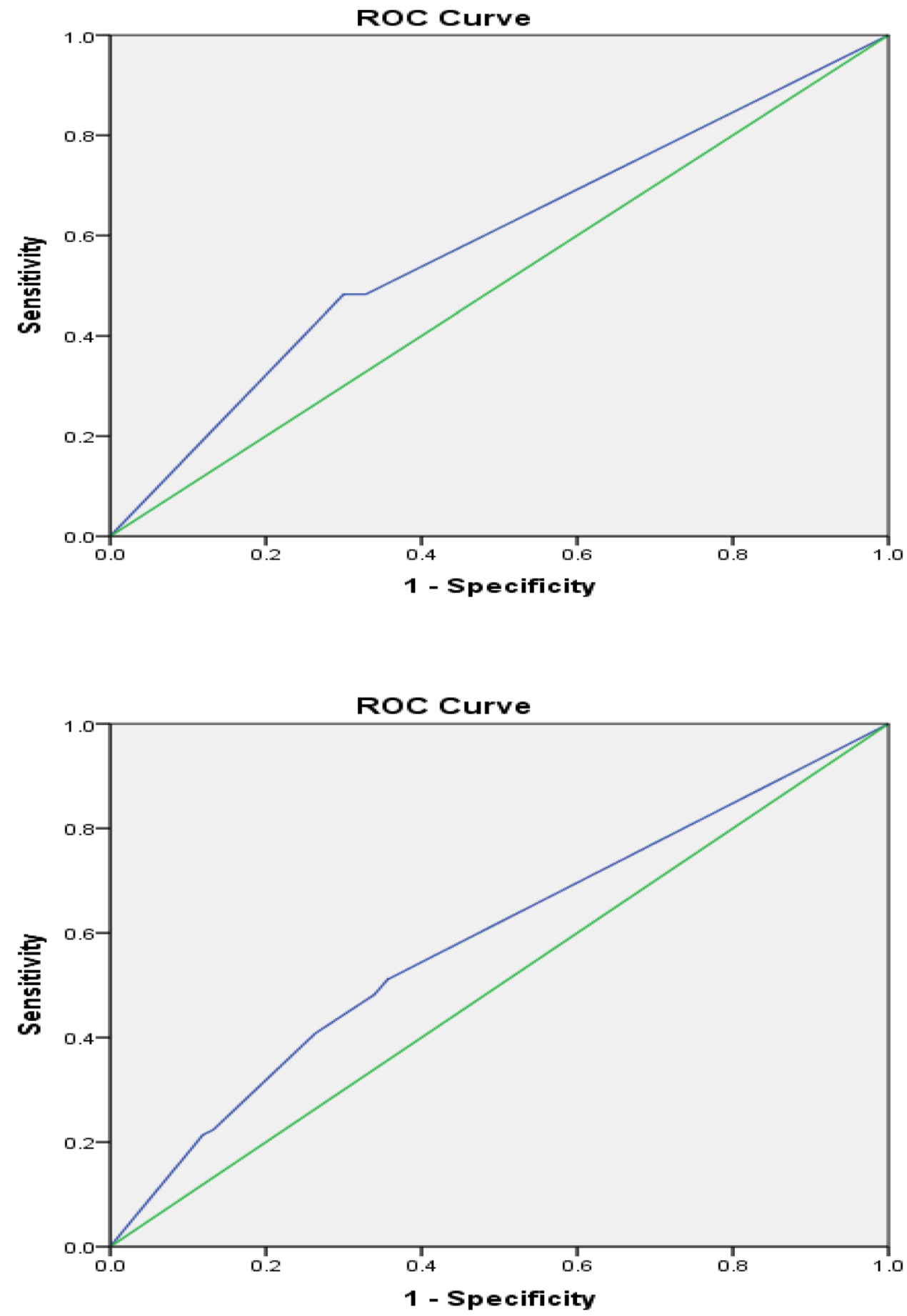
Fig. 7 Target Selection ROC Curve

Fig. 8 Combined (Inter-crime distance and target selection) ROC Curve
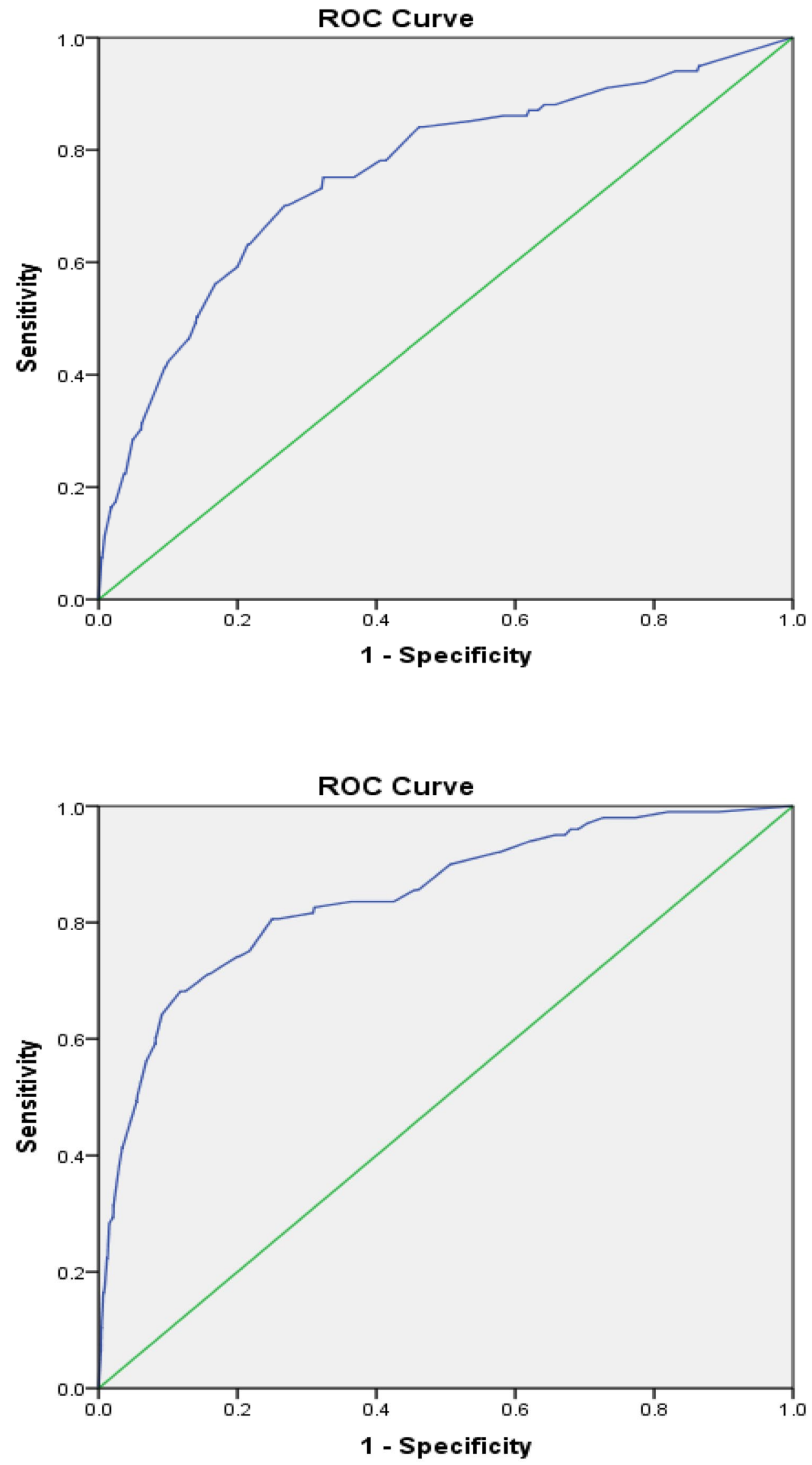


\section{References}

Addis N (2012) Exploring the impact and effectiveness of the 'Project Optimal' burglary reduction initiative in Leeds: A spatio-temporal approach. University of Leeds. https://www.geos.ed.ac.uk/ gisteac/ proceedingsonline/GISRUK2013/gisruk2013_submission_35.pdf

Albertetti F, Cotofrei P, Grossrieder L, Ribaux O, Stoffel K (2013) The CriLiM methodology: Crime linkage with a fuzzy MCDM approach. In: 2013 European Intelligence and Security Informatics Conference. pp 67-74. https://doi.org/10.1109/EISIC.2013.17

Bennell C, Canter D (2002) Linking commercial burglaries by modus operandi: tests using regression and ROC analysis. Sci Justice 42(3):153-164. https://www.sciencedirect.com/science/article/ abs/pii/S1355030602718200

Bennell C, Bloomfield S, Snook B, Taylor P, Barnes C (2010) Linkage analysis in cases of serial burglary: comparing the performance of university students, police professionals, and a logistic regression model. Psychol Crime Law 16(6):507-524. https://doi.org/ $10.1080 / 10683160902971030$

Bennell C, Jones NJ (2005) Between a ROC and a hard place: a method for linking serial burglaries by modus operandi. J Investig Psychol Offender Profiling 2:23-41. https://doi.org/10.1002/jip.21

Bennell C, Gauthier D, Gauthier D, Melnyk T, Musolino E (2010b) The impact of data degradation and sample size on the performance of two similarity coefficients used in behavioural linkage analysis. Forensic Sci Int 199:85-92. https://doi.org/10.1016/j. forsciint.2010.03.017

Borg A, Boldt M, Lavesson N, Melander U, Boeva V (2014) Detecting serial residential burglaries using clustering. Expert Syst Appl 41(11):5252-5266, ISSN 0957-4174. https://doi.org/10.1016/j. eswa.2014.02.035

Bouhana N, Johnson SD, Porter M (2016) Consistency and specificity in burglars who commit prolific residential burglary: Testing the core assumptions underpinning behavioural crime linkage. Leg Crim Psychol 21:77-94. https://doi.org/10.1111/lcrp.12050

Brantingham PJ, Brantingham PL (1993) Environment, routine and situation: Toward a pattern theory of crime. Adv Crim Theory 259-294. https://www.taylorfrancis.com/chapters/edit/10.4324/ 9781315128788-12/environment-routine-situation-toward-patterntheory-crime-patricia-brantingham-paul-brantingham

Burrell A, Bull R (2011) A preliminary examination of crime analysts' views and experiences of comparative case analysis. Int J Police Sci Manage 13:2-15. https://doi.org/10.1350/ijps.2011.13.1.212

Canter David V (2000) Offender profiling and criminal differentiation. Legal Crime Psychol 5(1):23-46. ISSN 1355-3259

Canter D V, Coffey T, Huntley M, Missen C (2000) Predicting serial killers' home base using a decision support system. J Quant Criminol 16 (4):457-478. ISSN 07484518

Canter D, Larkin P (1993) The environmental range of serial rapists. J Environ Psychol 13:63-69

Charnov E (1976) Optimal foraging: The marginal value theorem. Theor Popul Biol 9:2. https://www.sciencedirect.com/science/ article/pii/004058097690040X

Chatterjee S, Price B (1991) Regression analysis by example, 2nd edn. Wiley \& Sons, New York

Cohen L, Felson M (1979) Social change and crime rate trends: A routine activity approach. Am Sociol Rev 44(4):588-608. https:// www.jstor.org/stable/2094589?seq=1

Crime Linkage Internaonal Network (C-link) (2021) Retrieved January 25,2022 , from https://www.birmingham.ac.uk/generic/c-link/ index.aspx

Davies K, Tonkin M, Bull R, Bond JW (2012) The course of case linkage never did run smooth: A new investigation to tackle the behavioural changes in serial car theft. J Investig Psychol Offender Profiling 9(3):274-295. https://psycnet.apa.org/record/2012-27696-007
Davies K, Woodhams J (2019) The practice of crime linkage: A review of the literature. J Investig Psychol Offender Profiling 16:169-200. https://doi.org/10.1002/jip.1531

Ellingwood H, Mugford R, Bennell C, Melnyk T, Fritzon K (2013) Examining the role of similarity coefficients and the value of behavioural themes in 344 attempts to link serial arson offences. J Investig Psychol Offender Profiling

Fielding M, Jones V (2012) 'Disrupting the Optimal Forager': Predictive Risk Mapping and Domestic Burglary Reduction in Trafford, Greater Manchester. Sage Journals. https://doi.org/10.1350/ijps. 2012.14.1.260

Fortin MJ, Dale MRT (2005) Spatial analysis: a guide for ecologists. Cambridge University Press, New York

Fox BH, Farrington DP (2012) Creating burglary profiles using latent class analysis: A new approach to offender profiling. Crim Justice Behav 39:1582-1611. https://doi.org/10.1177/0093854812457921

Fox BH, Farrington DP (2014) Behavioral consistency among serial burglars: evaluating offense specialization using three analytical approaches. Crime Delinq 1-36. Advance online publication. https://doi.org/10.1177/0011128714540275

Halford E (2018) Assessing the optimal forager predictive policing approach to crime reduction and prevention intervention. The Police journal: Theory, practice and principles. For peer review. http://clok.uclan.ac.uk/29245/1/29245\%20Halfrod\%20Eric\% 20Final\%20e-Thesis\%20\%28Master\%20Copy\%29.pdf

Johnson SD (2014) How do offenders choose where to offend? Perspectives from animal foraging. Legal Criminol Psychol 19(2):193210. https://doi.org/10.1111/lcrp.12061

Johnson SD, Bowers KJ (2004a) Stability of space-time clusters of burglary. Br J Crimin 44:55-65. https://academic.oup.com/bjc/ article-abstract/44/1/55/380644? redirectedFrom=PDF

Johnson SD, Bowers KJ (2004b) The burglary as a clue to the future: The beginnings of prospective hot-spotting. Eu J Crim 1:237-255. https://doi.org/10.1177/1477370804041252

Johnson E, Payne J (1986) The Decision to Commit a Crime: An Information Processing Analysis. In: Cornish DB, Clarke RVG (eds) The Reasoning Criminal: Rational Choice Perspectives on Offending. Springer-Verlag, New York, pp 170-185

Johnson SD, Summers L, Pease K (2008) Offender as forager? A direct test of the boost account of victimization. J Quant Criminol 25(2):181-200. https://doi.org/10.1007/s10940-008-9060-8

Markson L, Woodhams J, Bond J (2010) Linking serial residential burglary: comparing the utility of modus operandi behaviours, geographical proximity, and temporal proximity. J Investig Psychol Offender Profiling 7(2):91-107. https://doi.org/10.1002/jip.120

Melnyk T, Bennell C, Gauthier DJ, Gauthier D (2011) Another look at across crime similarity coefficients for use in behavioural linkage analysis: An attempt to replicate Woodhams, Grant, and Price (2007). Psychol Crime Law 17:359-380. https://doi.org/10.1080/ 10683160903273188

Mugford R, Martineau M (2014) The ability of human judges to link crimes using behavioral information: Current knowledge and unresolved issues. In: Woodhams J, Bennell C (eds) Crime linkage: Theory, research, and practice. CRC Press, Boca Raton, FL, pp 251-278. https://doi.org/10.1201/b17591-12

Nee C, Meenaghan A (2006) Expert decision-making in burglars. Br J Crim 46:935-949. https://www.researchgate.net/profile/Claire-Nee/ publication/228223898_Expert_Decision_Making_in_Burglars/links/ 552fbd6d0cf2f2a588a92b88/Expert-Decision-Making-in-Burglars. pdf

Office for National Statistics (ONS) (2021) Crime in England and Wales: Year ending June 2021. Office for National Statistics. https://www. ons.gov.uk/peoplepopulationandcommunity/crimeandjustice/bulletins/ crimeinenglandandwales/ingjune2021\#theftoffences 
Opp KD (1997) Limited rationality and crime. In: Newman G, Clarke RVG, Shoham SG (eds) Rational choice and situational crime prevention: Theoretical foundations. Ashgate, Aldershot, pp 52-75

Orians GH, Pearson NE (1979) On the theory of central place foraging. In: Horn DF (ed) Analysis of ecological systems. Ohio State University Press, Columbus, pp 157-177

Pakkanen T, Zappalà A, Grönroos C, Santtila P (2012) The effects of coding bias on estimates of behavioural similarity in crime linking research of homicides. J Investig Psychol Offender Profiling 9:223-234. https://doi.org/10.1002/jip.1366

Peng C-YJ, Lee KL, Ingersoll GM (2002) An introduction to logistic regression analysis and reporting. J Educ Res 96(1):3-14. https:// doi.org/10.1080/00220670209598786

Pitcher AB, Johnson SD (2011) Exploring theories of victimization using a mathematical model of burglary. J Res Crime Delinq 48(1):83-109. https://doi.org/10.1177/0022427810384139

Pyke G (2019) Animal movements: an optimal foraging approach. In: Choe JC (ed) Encyclopedia of animal behavior, 2nd edn, vol 2. Elsevier Academic Press, pp 149-156). https://www.sciencedirect. com/science/article/pii/B9780128096338901602?via\%3Dihub

Pyke G, Pulliam H, Charnov E (1977) Optimal foraging: A selective review of theory and tests. Q Rev Biol 52(2):137-154. Retrieved April 20, 2021, from http://www.jstor.org/stable/2824020

Ratcliffe J, Rengert G (2008) Near-repeat patterns in Philadelphia shootings. Secur J 21:58-76. https://doi.org/10.1057/palgrave.sj. 8350068

Reich B, Porter M (2015) Partially supervised spatiotemporal clustering for burglary crime series identification. J R Stat Soc 178(2):465-480. https://doi.org/10.1111/rssa.12076

Rossmo DK (2000) Geographic profiling. CRC Press

Rodríguez J, Guillermo Z, Ana M (2019) Does optimal foraging theory explain the behavior of the oldest human cannibals? J Human Evol 131:228-239. ISSN 0047-2484. https://doi.org/10.1016/j. jhevol.2019.03.010

Salo B, Sirén J, Corander J, Zappalà A, Bosco D, Mokros A, Santtila P (2013) Using Bayes' theorem in behavioural crime linking of serial homicide. Legal Criminol Psychol 18:356-370. https://doi. org/10.1111/j.2044-8333.2011.02043.x

Santilla P, Korpela K, Hakkanen H (2004) Expertise and decision making in the linkage of car crime series. Psychol Crime Law 10(2). https://doi.org/10.1080/1068316021000030559

Swets J (1992) The science of choosing the right decision threshold in high-stakes diagnostics. Am Psychol 47:522-532. https://doi.org/ 10.1037/0003-066X.47.4.522
Swets J, Dawes R, Monahan J (2000) Better decisions through science. Scientific American. https://doi.org/10.1038/scientificamerican100082

Taylor E (2014) Honour among thieves? Exploring the morality and rationality of convicted domestic burglars. Criminol Crim Justice. An International Journal 14(4):487-502

Tonkin M (2012) Behavioural case linkage: Generalisability, ecological validity, and methodology (unpublished doctoral dissertation). University of Leicester, UK

Tonkin M, Grant TD, Bond JW (2008) To link or not to link: a test of the case linkage principles using serial car theft data. J Investig Psychol Offender Profiling 5(1-2):58-77. https://doi.org/10.1002/ jip.74

Tonkin M, Santtila P, Bull R (2011) The linking of burglary crimes using offender behaviour: Testing research cross-nationally and in more realistic settings. Legal Criminol Psychol. Advance online publication. https://doi.org/10.1111/j.2044-8333.2010.02007.x

Tonkin M, Woodhams J (2017) The feasibility of using crime scene behaviour to detect versatile serial offenders: An empirical test of behavioural consistency, distinctiveness and discrimination accuracy. Legal Criminol Psychol 22:99-115

Turvey B, Freeman J (2016) Applied case linkage analysis. In: Turvey BE, Esparza MA (eds) Behavioral evidence analysis. Academic Press, pp 299-335. ISBN 9780128006078. https://doi.org/10. 1016/B978-0-12-800607-8.00016-1

Wang T, Rudin C, Wagner D, Sevieri R (2015) Finding patterns with a rotton core: data mining for crime series with cores. Big Data 3(1). https://doi.org/10.1089/big.2014.0021?src=recsys

Woodhams J, Tonkin M, Burrell A, Imre H, Winter JM, Lam EKM, ten Brinke GJ, Webb M, Labuschagne G, Bennell C, Ashmore-Hills L, van der Kemp J, Lipponen S, Pakkanen T, Lee Rainbow C, Salfati G, Santtila P (2019) Linking serial sexual offences: Moving towards an ecologically valid test of the principles of crime linkage. Legal Criminol Psychol 24:123-140. https://doi.org/10. 1111/lcrp. 12144

Zoete J, Sjerps M, Lagnado D, Fenton N (2015) Modelling crime linkage with Bayesian networks. Sci Justice 55(3):209-217. ISSN 1355-0306. https://doi.org/10.1016/j.scijus.2014.11.005

Publisher's Note Springer Nature remains neutral with regard to jurisdictional claims in published maps and institutional affiliations. 